\title{
Manejo del paciente grave y crítico
}

\author{
Severe and critical patient management
}

Elsa Gabriela Saucedo Rodríguez,* Mario Arturo Flores Valadez,*

Elieth Ochoa García, ${ }^{\ddagger}$ Alejandro Alejandre García, ${ }^{\S}$ Rosangela Del Razo Rodríguez, ${ }^{\natural}$ Emma Rosario García Colín," María Silvia Lule Morales, ${ }^{* *}$ Marco Antonio Iñiguez García, ${ }^{\ddagger}$ David Méndez Martínez, ${ }^{\S \S}$ Olga García Oropeza ${ }^{\natural \uparrow}$

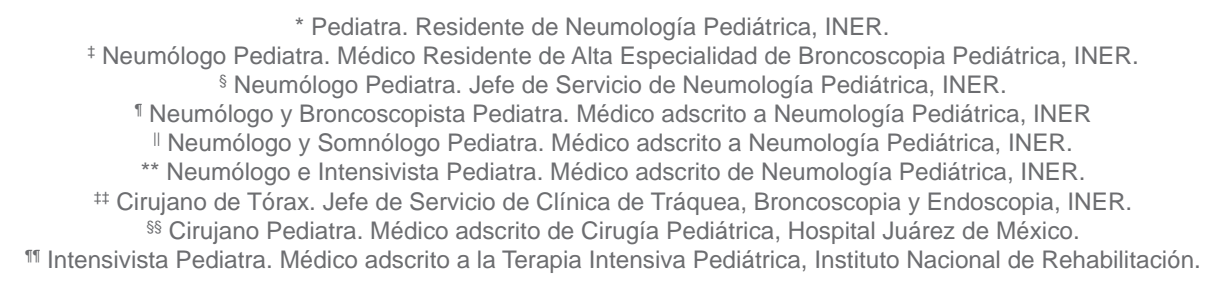

El reconocimiento del paciente grave y crítico con COVID-19 incluye monitorearlo para detectar algún deterioro clínico y falla respiratoria rápidamente progresiva y sepsis, además de poder iniciar intervenciones de soporte. La aplicación de las estrategias efectivas, seguras y a buen tiempo es la piedra angular del tratamiento de las manifestaciones graves de COVID-19. Desde el ingreso del paciente, deben realizarse pruebas de laboratorio hematológicas y bioquímicas, así como electrocardiograma y, si clínicamente se indica, monitoreo de las complicaciones como daño hepático, renal, cardiaco o choque. Se recomienda tomar hemocultivos de bacterias que provocan neumonía y septicemia antes de administrar el tratamiento con antimicrobianos, pero no retrasar el tratamiento con antimicrobianos hasta obtener el hemocultivo; ${ }^{1}$ por lo tanto, si se sospecha sobreinfección bacteriana que causa SIRA o sepsis, los antibióticos deben iniciarse lo antes posible, es decir, en la primer hora de manejo inicial del paciente. ${ }^{2}$ Siempre debe tenerse en cuenta las comorbilidades y los tratamientos previos, los cuales pueden ser suspendidos temporalmente hasta que el paciente se haya estabiliza-

Financiamiento: Ninguno.

Conflicto de intereses: Ninguno.

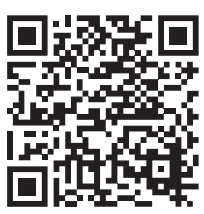

do; también deben monitorearse las interacciones farmacológicas.

Hay que considerar que se dé oxígeno suplementario inmediato a los pacientes con COVID-19 con síntomas graves y dificultad respiratoria, hipoxemia o choque, para que se mantengan saturaciones adecuadas $\left(\mathrm{SpO}_{2}>90 \%\right.$ a nivel de la Ciudad de México y > 94\% a nivel del mar). ${ }^{3}$ Para ello, los niños pequeños pueden usar puntas nasales. En adolescentes se inicia la oxigenoterapia a $5 \mathrm{~L} /$ min y se titula a mantener $\mathrm{SpO}_{2}>93 \%$ con uso de mascarilla reservorio (a 10-15 L/min, $\mathrm{FiO}_{2} 0.60-0.95$ ) si el paciente está en condición crítica.

\section{SÍNDROME DE INSUFICIENCIA RESPIRATORIA AGUDA (SIRA)}

Si el paciente continúa hipoxémico, a pesar de usar una mascarilla con reservorio (flujo de $10-15 \mathrm{~L} / \mathrm{min}$, $\mathrm{FiO}_{2}$ 0.60-0.95) y se reconoce que hay una falla respiratoria hipoxémica en un paciente con dificultad respiratoria, se debe dar soporte ventilatorio avanzado con oxígeno. La falla respiratoria hipoxémica del SIRA, frecuentemente, se debe al incremento del V/Q o shunt, que, muchas veces, requiere ventilación mecánica. La intubación endotraqueal debe realizarse

Citar como: Saucedo REG, Flores VMA, Ochoa GE, Alejandre GA, Del Razo RR, García CER et al. Manejo del paciente grave y crítico. Rev Latin Infect Pediatr. 2020; 33 (s1): s52-s69. https://dx.doi.org/10.35366/96671 
Rev Latin Infect Pediatr 2020; 33 (s1): s52-s69

por personal experimentado que use las precauciones necesarias. La secuencia rápida de intubación es apropiada cuando no se identifiquen datos de intubación difícil. ${ }^{4}$ Dado que los niños tienen una mayor y más rápida desaturación, se sugiere preoxigenar con $\mathrm{FiO}_{2}$ a $100 \%$ durante 5 minutos, con una bolsa válvula mascarilla con reservorio, aunque se recomienda para este fin, el uso de PAF o de la VMNI.

\section{RECOMENDACIONES DE LA VENTILACIÓN MECÁNICA DE LOS NIÑOS CON SIRA}

Dentro de lo posible, dé ventilación mecánica usando VT bajos (4-8 $\mathrm{mL} / \mathrm{kg}$ del $\mathrm{PI}$ ) y presiones inspiratorias bajas (presión meseta $\leq 30 \mathrm{cmH}_{2} \mathrm{O}$ ).

A continuación, mencionaremos las recomendaciones en niños y adolescentes, que están basadas en recomendaciones consensuadas para niños ${ }^{5}$ y de la OMS ${ }^{1}$ (Tabla 1).

En pacientes con SIRA de moderado a grave $\left(\mathrm{PaO}_{2} / \mathrm{FiO}_{2} \leq 150\right)$, que no tienen hipoperfusión, utilice líquidos limitados, ya que se ha visto que disminuyen el tiempo requerido de ventilación mecánica. El uso de bloqueadores neuromusculares en infusión continua no debe usarse de rutina, ${ }^{6}$ aunque en niños puede usarse en casos de hipoxemia y/o hipercapnia refractaria, así como asincronía del ventilador, a pesar de la sedación; en estos pacientes el volumen tidal debe ser limitado.

Se sugiere el uso de PEEP alto más que bajos. ${ }^{1}$ La titulación del PEEP requiere considerar los riesgos y beneficios (Figura 1). Podemos seguir las tablas de titulación de PEEP con base en los requerimientos de $\mathrm{FiO}_{2}$ para mantener la $\mathrm{SpO}_{2}$. Como se menciona en el resumen del protocolo de ventilación mecánica ARDSnet, ${ }^{7}$ los criterios de inclusión adecuados en adolescentes son:
Instalación aguda de:

1. $\mathrm{PaO}_{2} / \mathrm{FiO}_{2} \leq 300$ (corregida por altitud).

2. Radiopacidades bilaterales en parche, difusos u homogéneos.

3. Que no haya evidencia de sobrecarga atrial izquierda.

Parte I. Parámetros de ventilador iniciales y ajustes:

1. Calcular según el PI del paciente:

Masculinos $=50+2.3$ (talla [pulgadas] -60$)$

Femeninos $=45.5+2.3$ (talla [pulgadas] -60$)$

2. Seleccionar cualquier modo ventilatorio.

3. Programar parámetros iniciales con un VT $=8 \mathrm{~mL}$ $\mathrm{kg} \mathrm{PI}$.

4. Disminuir VT a $1 \mathrm{~mL} / \mathrm{kg}$ a intervalos de $\geq 2$ horas hasta un VT $=6 \mathrm{~mL} / \mathrm{kg} \mathrm{PI}$.

5. Seleccionar la FR inicial para dar la ventilación mecánica (en adolescentes no más de $35 \mathrm{rpm}$ ).

6. Ajustar el VT y la FR según las metas de $\mathrm{pH}$ y presión meseta.

A. Las metas de oxigenación son: $\mathrm{PaO}_{2} 55-80$ $\mathrm{mmHg} \circ \mathrm{SpO}_{2} 88-95 \%$, recomendándose el uso del mínimo (PEEP de $5 \mathrm{cmH}_{2} \mathrm{O}$ ). Considerar el incremento de $\mathrm{FiO}_{2} / \mathrm{PEEP}$ y sus combinaciones según se recomienda en la Tabla 2.

B. La meta de la presión meseta es $<30 \mathrm{cmH}_{2} \mathrm{O}$; para ello, sugerimos:

Checar la Pplat o meseta con 10 segundos de pausa inspiratoria, por lo menos cada cuatro horas y después de cada cambio de PEEP o de VT.

- Si la Pplat $\geq 30 \mathrm{cmH}_{2} \mathrm{O}$ : disminuya el VT en $1 \mathrm{~mL} / \mathrm{kg}$ cada escalón (mínimo $=4 \mathrm{~mL} / \mathrm{kg}$ ).

- Si la Pplat $\leq 25 \mathrm{cmH}_{2} \mathrm{O}$ y VT $\leq 6 \mathrm{~mL} / \mathrm{kg}$, incremente el VT en $1 \mathrm{~mL} / \mathrm{kg}$ hasta una Pplat $\geq 25 \mathrm{cmH}_{2} \mathrm{O}$ o VT $6 \mathrm{~mL} / \mathrm{kg}$.

Tabla 1: Recomendaciones de parámetros iniciales del ventilador en pacientes pediátricos críticos con COVID-19.

Adolescentes

- Volumen tidal de $6 \mathrm{~mL} / \mathrm{Kg}$ calculado por PI, sabiendo que el volumen tidal superior a $8 \mathrm{~mL} / \mathrm{Kg}$ PI puede llevar a efectos indeseables como asincronía y $\mathrm{pH}<7.15$

- Hipercapnia permisiva

- La sedación profunda puede ayudar a mejorar el control respiratorio y de los volúmenes

- Se recomienda pronar a los pacientes con SIRA grave durante 12-16 horas por día
Niños

- Presión meseta baja $\left(\leq 28 \mathrm{cmH}_{2} \mathrm{O}\right)$ a llevar como objetivo un pH permisivo de 7.15 a 7.30

- Los volúmenes tidales aceptados según la severidad:

- 3-6 mL/Kg PI en caso de pobre complianza

- 5-8 mL/Kg PI para pacientes con mejor preservación de la complianza

- Puede considerarse pronar a los pacientes pediátricos 


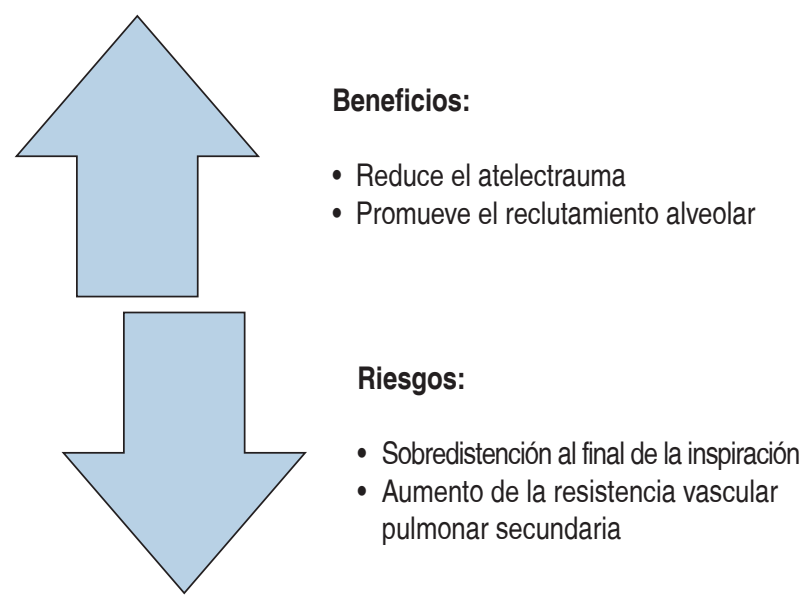

Figura 1: Beneficios y riesgos del uso de PEEP altos.

- Si la Pplat $\leq 30 \mathrm{cmH}_{2} \mathrm{O}$ y hay asincronía se puede incrementar el VT en $1 \mathrm{~mL} / \mathrm{kg}$ hasta $7 \mathrm{u} 8 \mathrm{~mL} / \mathrm{kg}$ si la Pplat se mantiene $\leq 30$ $\mathrm{cmH}_{2} \mathrm{O}$.

Evite desconectar al paciente del ventilador, por ejemplo, durante la aspiración, puesto que esto no permitirá que se pierda el PEEP y cause atelectasias; para ello, debemos usar circuitos de aspiración cerrados.

Respecto a las consideraciones de sistema de ECMO, en adultos no se encontró mejoría del SIRA a 60 días entre ECMO y ventilación mecánica convencional, incluyendo la posición prono y bloqueo neuromuscular, pero puede que disminuya la mortalidad. ${ }^{8}$ En pacientes con SDRA grave, se recomienda la ventilación mecánica en decúbito prono durante más de 12 horas, lo cual, también está recomendado para niños y adultos. ${ }^{9}$ Existen reportes no publicados de que, al momento de poner al paciente en posición prono y despierto, podría evitarse la intubación, pero se necesitan más estudios al respecto. ${ }^{10}$

Basándonos en estudios donde se administraron corticosteroides para tratar la infección por MERS, no fue observado ningún efecto de su uso respecto de la mortalidad, sino una eliminación tardía del MERS-CoV de las vías respiratorias bajas. ${ }^{11}$ Dada la falta de eficacia y la posibilidad de daños, debería evitarse su administración, a menos que se indiquen por alguna otra razón.

Si el paciente tiene broncoespasmo, se evitará la administración de aerosoles. Si es necesario aplicar medicamentos inhalados como broncodilatadores, sólo se utilizarán con válvulas unidireccionales en la rama inspiratoria al circuito del ventilador o dispositivos de malla vibratoria, como se mencionó en el capítulo de tratamiento. ${ }^{12}$

Existe una publicación del Colegio Oficial de Ingenieros Industriales de Madrid que reporta un protocolo para situaciones de pandemia/catástrofe sanitaria ${ }^{13}$ y que contempla la implementación de tubos conectores para que un solo ventilador pueda ser usado por dos pacientes, con la finalidad de aumentar la supervivencia. Sin embargo, se publicó una declaración de marzo de 2020, de la posición de la Society of Critical Care Medicine, American Association for Respiratory, la Sociedad Americana de Anestesiólogos, la Fundación de Seguridad del Paciente con Anestesia, la Asociación Americana de las Enfermeras de Cuidados Críticos y el American College of Chest Physicians que aborda la escasez de ventiladores del 2019 al 2020 debido al brote de COVID-19. La sociedad recomienda no compartir el ventilador debido a la seguridad del paciente, a los desafíos logísticos y las preocupaciones éticas, y recomienda priorizar el triaje y la ventilación en la mayoría de los pacientes, pues así, es probable que éstos se beneficien del soporte mecánico y se recuperen de la enfermedad como alternativa a la ventilación compartida. ${ }^{14}$

\section{VENTILACIÓN MECÁNICA NO INVASIVA (VMNI) Y PUNTAS NASALES DE ALTO FLUJO (PAF)}

Existen opciones como la VMNI para pacientes con COVID-19 sintómatico leve o moderado y dificultad respiratoria. Se puede implementar como estrategia preventiva para evitar la intubación orotraqueal (sin retrasarla en caso de ser necesaria) y reducir el trabajo respiratorio; también puede ser utilizada para ganar tiempo y conseguir otra forma de sostén invasivo (por ejemplo, ventiladores no disponibles o lugar en $\mathrm{UCl}){ }^{1}$ La selección del soporte respiratorio para pacientes afectados por SARS-CoV-2 debe

\begin{tabular}{|c|c|c|c|c|c|c|c|c|}
\hline \multicolumn{9}{|c|}{$\begin{array}{l}\text { Tabla 2: Tabla de incremento de } \mathrm{FiO}_{2} / \\
\text { PEEP y sus combinaciones. }\end{array}$} \\
\hline \multicolumn{9}{|c|}{ Alto $\mathrm{PEEP} /$ bajo $\mathrm{FiO}_{2}$} \\
\hline $\mathrm{FiO}_{2}$ & 0.3 & 0.3 & 0.3 & 0.3 & 0.3 & 0.4 & 0.4 & 0.5 \\
\hline PEEP & 5 & 8 & 10 & 12 & 14 & 14 & 16 & 16 \\
\hline $\mathrm{FiO}_{2}$ & 0.5 & $0.5-0.8$ & 0.8 & 0.9 & 1.0 & 1.0 & & \\
\hline PEEP & 18 & 20 & 22 & 22 & 22 & 24 & & \\
\hline
\end{tabular}




\section{Tabla 3: Flujo de aire según peso.}

Peso (kg)

Flujo $(\mathrm{L} / \mathrm{m})$

$\begin{array}{cc}3-4 & 5 \\ 4-7 & 6 \\ 8-10 & 7-8 \\ 11-14 & 9-10 \\ 15-20 & 10-15 \\ 21-25 & 15-20 \\ >30 & \geq 25\end{array}$

tener un equilibrio entre el beneficio clínico con el riesgo de dispersión aérea nosocomial así como las características clínicas y gasométricas. ${ }^{15,16}$

A manera de recordatorio, la IR se clasifica en dos grupos:

- IR tipo I: hipoxémica, principalmente por alteración en la relación $\mathrm{V} / \mathrm{Q}$. Es la forma más común de IR aguda y puede evolucionar a IR tipo II. ${ }^{17,18}$

- IR tipo II: hipercápnica, asociada a hipoxemia, es causada por depresión del centro respiratorio y/o fatiga de músculos de la respiración. . $^{17,18}$

Con base en esto, se elegirá el modo ventilatorio, la interfaz y el circuito más adecuado.

La ventilación mecánica no invasiva facilita la función respiratoria del paciente; ésta se administra a través de una mascarilla (interfaz), dejando intactos los mecanismos de defensa de la vía aérea superior con el objetivo de incrementar la ventilación alveolar y proveer reposo muscular. ${ }^{19}$ Todas las formas de oxígeno suplementario y soporte respiratorio pueden aerosolizar potencialmente el patógeno; por esta razón, su uso está indicado solamente para personal capacitado que cuente con el EPP adecuado, lo que permite disminuir el riesgo de contagio. ${ }^{20}$ Además, es preferible contar con habitaciones de presión negativa.

Los factores que se asocian con fallo y mal pronóstico respecto del uso de VMNI son: SDRA grave, choque séptico y falla orgánica múltiple. Por lo tanto, su uso debe evitarse en cualquiera de estas condiciones. ${ }^{21}$

\section{OXÍGENO NASAL DE ALTO FLUJO (ONAF)}

Permite calentar y humidificar los flujos de aire para su administración a través de una cánula nasal con la que se pueden tolerar flujos más altos. Los sistemas ONAF para adultos pueden entregar $60 \mathrm{~L} / \mathrm{min}$ de flujo. Los circuitos pediátricos generalmente sólo manejan hasta $25 \mathrm{~L} / \mathrm{min}$; en caso de ameritar mayor flujo, se pueden utilizar sistemas para adultos, ajustando el tamaño de la cánula nasal (Tabla 3). 15,20,22

Dispositivos

- Cánula nasal de alto flujo (Figura 2).

- Insuflación nasal de alta velocidad.

Indicaciones ${ }^{23}$

- IR Aguda tipo I o disnea leve refractaria a tratamiento convencional, sin fatiga muscular.

Ventajas ${ }^{15,16}$

- Aporta una fracción de oxígeno más elevada y constante.

- Reduce el espacio muerto nasofaríngeo.

- Genera presión positiva.

- Disminuye mínimamente el trabajo respiratorio.

- Hay mayor comodidad y tolerabilidad.

- Está asociada con menor mortalidad en IR aguda (versus terapia convencional).

- Menor riesgo de intubación subsecuente (versus terapia convencional).

Desventajas $^{24}$

- No produce reclutamiento alveolar definitivo.

- No es útil en el tratamiento de hipercapnia o fatiga muscular.

Contraindicaciones ${ }^{1,15}$

- Inicio con $\mathrm{pH}<7.30$.

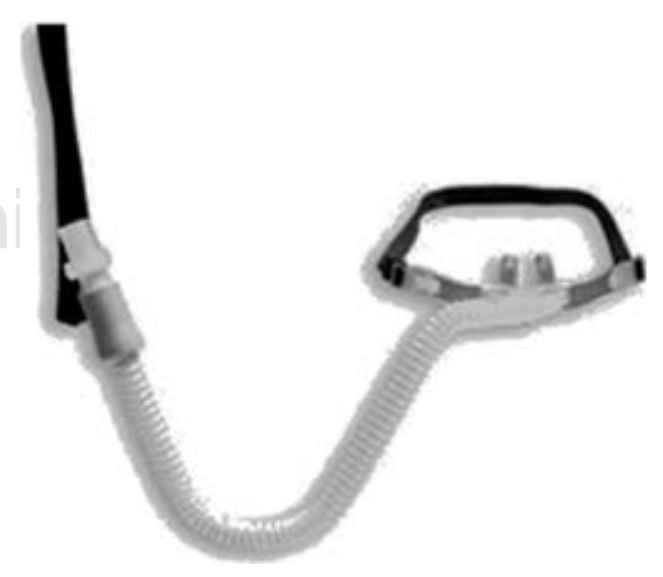

Figura 2: Cánula nasal de alto flujo. 
- Pacientes con hipercapnia aguda o crónica.

- Inestabilidad hemodinámica.

- Falla orgánica múltiple.

- Alteración del estado neurológico.

\section{PRESIÓN POSITIVA CONTINUA EN LA VÍA RESPIRATORIA (CPAP)}

Genera una presión mayor a la atmosférica durante todo el ciclo respiratorio y aumenta la presión media de la VAS con el consecuente incremento de la CRF, disminuyendo el desarrollo y/o progresión de atelectasias y reclutamiento alveolar, lo que mejora la oxigenación. Sin embargo, no apoya activamente a los músculos respiratorios y no ayuda en la entrega de VC. ${ }^{25}$

Es útil únicamente en IR aguda tipo I sin fatiga de músculos de la respiración.

Indicaciones ${ }^{23}$

- IR aguda tipo I.

- $\mathrm{PaO}_{2} / \mathrm{FiO}_{2}<200 \mathrm{mmHg}$.

- $\mathrm{PaCO}_{2}<45 \mathrm{mmHg}$ y $\mathrm{pH}>7.20$.

- Paciente colaborador, hemodinámicamente estable, capaz de mantener la vía aérea permeable y de manejar secreciones respiratorias.

Contraindicaciones ${ }^{23}$

- IR aguda tipo II.

- Inestabilidad hemodinámica.

- Falla multiorgánica múltiple.

- Alteración del estado neurológico. Glasgow < 9 .

- Imposibilidad de manejar secreciones bronquiales o secreciones abundantes.

- Falta de colaboración del paciente o negativa del paciente.

\section{PRESIÓN SOPORTE BINIVEL}

Ofrece dos niveles de presión distintos en inspiración y espiración, lo que permite un ajuste independiente de la EPAP y de la IPAP, generando una presión de soporte mantenida durante todo el ciclo inspiratorio espontáneo del paciente. ${ }^{25}$

Existen tres modalidades: ${ }^{23}$

- Espontáneo (S): el respirador cicla entre los niveles de IPAP y EPAP siguiendo el ritmo respiratorio del paciente.

- Controlado por tiempo (T): cicla entre los niveles de IPAP y EPAP según una frecuencia respiratoria programada y finaliza tras un tiempo inspiratorio prefijo.

- Modo espontáneo tiempo (ST): el respirador cicla como en el modo espontáneo, pero si el paciente es incapaz de iniciar una respiración, el ventilador inicia el ciclo. Este modo es el preferido, ya que, además de mejorar la oxemia y disminuir la hipercapnia, también ayuda activamente a los músculos de la respiración.

\section{Indicaciones ${ }^{26}$}

- IR tipo I con fatiga muscular, sin respuesta a terapias previas como ONAF o CPAP, IR tipo II con o sin fatiga muscular.

- SDRA leve o moderado que permita mejorar el intercambio gaseoso, disminuir el trabajo respiratorio y tratar de evitar las complicaciones de la ventilación mecánica.

- Se recomienda en niños con factores de riesgo (por ejemplo, inmunodeficiencias), a causa del alto riesgo de complicaciones con ventilación mecánica invasiva.

- Paciente colaborador, hemodinámicamente estable, capaz de mantener la vía aérea permeable y de manejar secreciones respiratorias.

En la Figura 3 se muestra un algoritmo diseñado para el uso de VMNI que comprende las tres modalidades antes descritas. ${ }^{21,27}$

Contraindicaciones ${ }^{23}$

- Inestabilidad hemodinámica.

- Falla multiorgánica múltiple.

- Alteración del estado neurológico. Glasgow < 9 .

- Imposibilidad de manejar secreciones bronquiales o secreciones abundantes.

- Falta de colaboración del paciente o negativa del paciente.

\section{TIPO DE INTERFAZ (MASCARILLA)}

- Nasal: genera un menor espacio muerto y permite la alimentación. Precisa la boca cerrada para evitar fugas. Es posible utilizar un arnés para sujetar el mentón; si el paciente no colabora, es mejor utilizar interfaz nasobucal (Figura 4A). ${ }^{28}$

- Nasobucal: cubre nariz y boca, consigue un mejor control de las presiones y es más adecuada en situaciones agudas. Produce menos fugas y tolera presiones elevadas (Figura 4B).

- Facial completa: cubre la totalidad de la cara, tiene un mayor espacio muerto y menos fugas (Figura 4C). 
Rev Latin Infect Pediatr 2020; 33 (s1): s52-s69

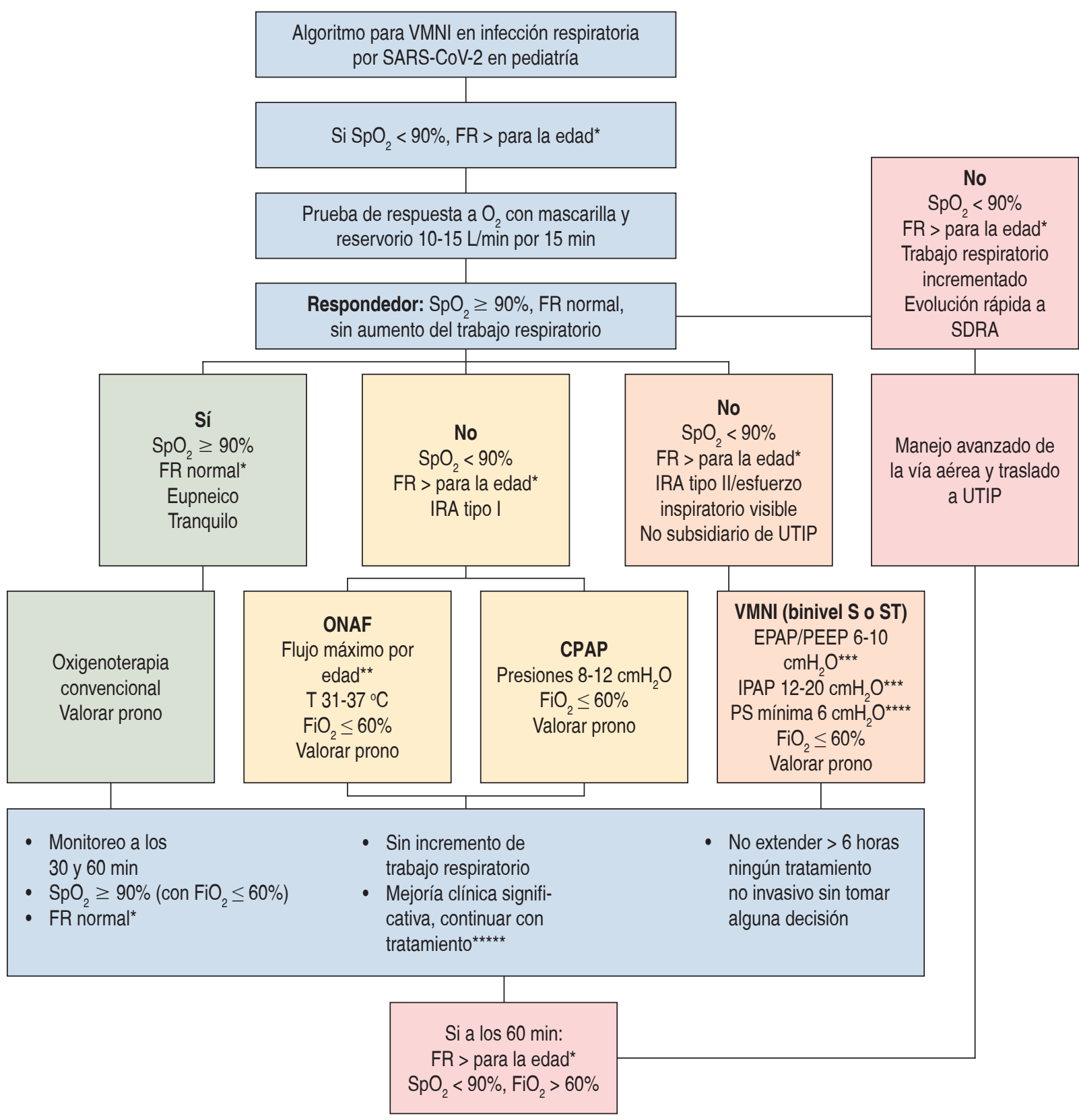

\footnotetext{
* Frecuencia respiratoria normal para la edad por la American Heart Association (AHA): para el lactante es de 30-35 rpm; lactante mayor (1-2 años), de 22-37 rpm; preescolar, de 20-28 rpm; escolar, de 18-25 rpm, y adolescente, de 12-20 rpm.

** Incremento progresivo hasta conseguir efecto deseado. Flujos máximos orientativos son $12 \mathrm{~L} / \mathrm{m}$ en $<1$ año, $30 \mathrm{~L} / \mathrm{m}>1$ año y $60 \mathrm{~L} / \mathrm{m}$ en adolescentes/adultos.

*** Iniciar con presiones mínimas e incrementar hasta hallar una presión deseada.

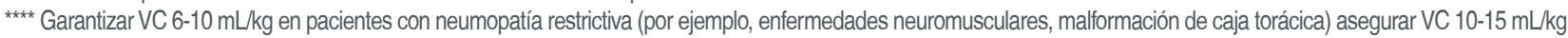

***** Criterios de mejoría clínica:

$\checkmark$ FR $30 \%$ de la inicial

$\checkmark$ FC 20\% de la inicial

仓 $\mathrm{PaO}_{2}(\geq 60-70 \mathrm{mmHg}), \mathrm{SpO}_{2}, \mathrm{pH}$

\& $\mathrm{PCO}_{2}(\leq 50 \mathrm{mmHg})$

$\checkmark$ Trabajo respiratorio y requerimiento de oxígeno suplementario
}

Figura 3: Tomado y adaptado de recomendaciones para el manejo de la insuficiencia respiratoria aguda hipoxémica por COVID-19.8,14 

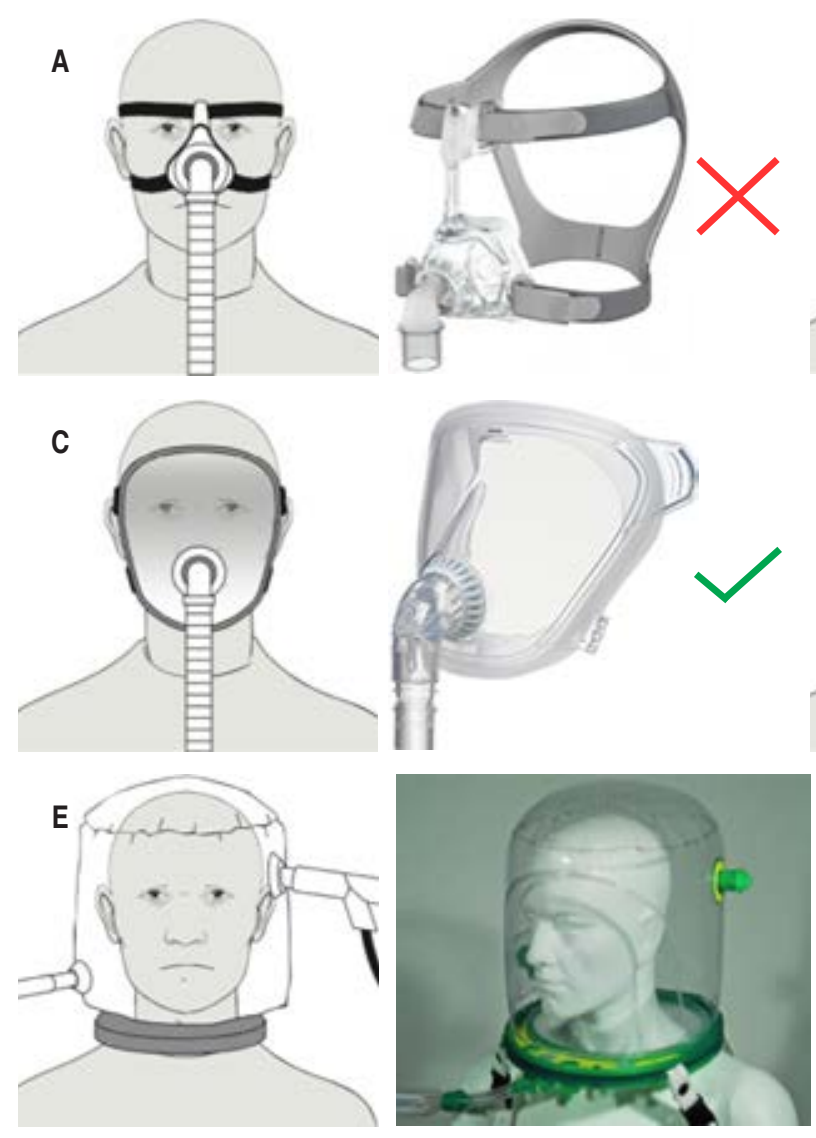
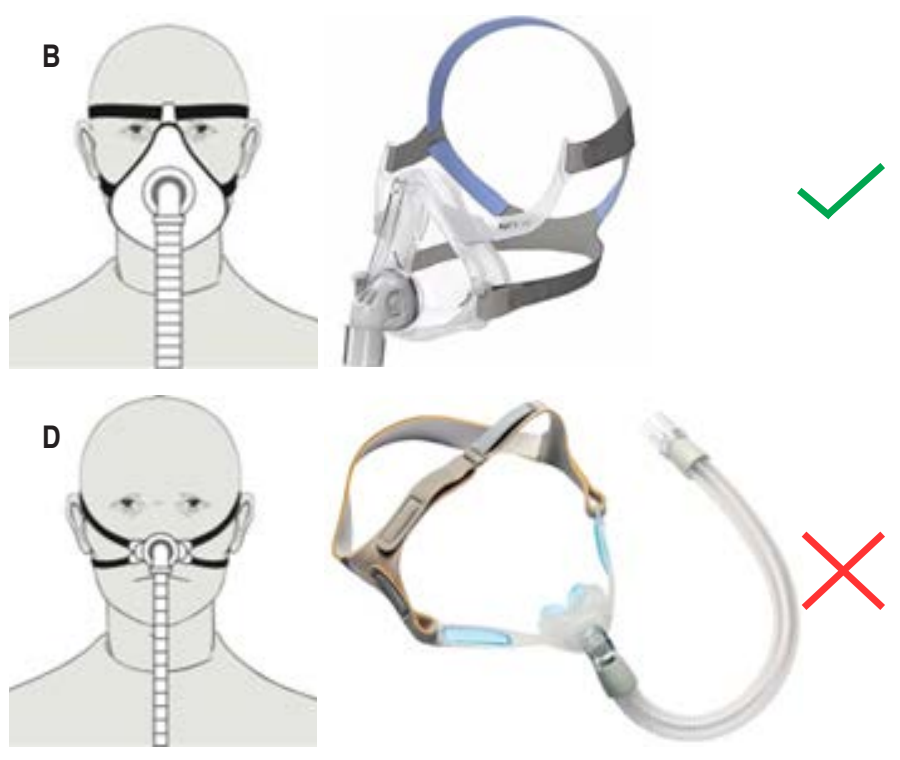

- Almohadillas nasales: interfaz con almohadillas que sellan los orificios nasales desde el exterior y se dirige hacia la frente. No tolera presiones altas y producen más fugas (Figura 4D).

- Casco (helmet): dispositivo transparente que cubre toda la cabeza hasta el cuello. Tiene un elevado espacio muerto, por lo que necesita un flujo alto para evitar la reinhalación (Figura 4E). 17,28

Las recomendaciones para el uso de interfaz en pacientes con COVID-19 son las siguientes: ${ }^{27}$

a) Uso de interfaz nasobucal, facial completa o casco, debido a una menor fuga y aerosolización.

b) Se deberá colocar la máscara y luego encender el equipo. Al término, primero, se debe apagar el equipo y luego desconectar la interfaz (no retirar el filtro de la interfaz en caso de recambio o apertura del circuito).

La VMNI es un sistema no hermético con dos tipos de fugas: las intencionales, dadas por los puertos de exhalación, que tienen el objetivo de evitar la reinhala- ción de $\mathrm{CO}_{2}$, y las cuales se compensan automáticamente por el equipo, y las no intencionales ocasionadas por un mal ajuste o una mala elección de la interfaz, por lo que se debe elegir el circuito ideal, dependiendo de la interfaz disponible. El incremento en la fuga no intencional influye en el VC efectivo (Figura 5). ${ }^{28}$

Algunas recomendaciones sobre los circuitos de ventilación en pacientes con COVID-19 son:

a) Utilizar circuitos de doble rama (una inspiratoria y otra espiratoria) con mascarilla no ventilada (codo azul) y filtro pediátrico de alta eficiencia con retención bacteriológica/viral y con baja resistencia (Figura 6A) en la rama espiratoria (Figura 4C).

b) En caso de utilizar un circuito único, la interfaz debe ser nasobucal no ventilada (codo azul) y tener una válvula de exhalación activa en el circuito junto con un filtro de alta eficiencia con retención bacteriológica/viral y con baja resistencia (Figura 6B).

c) Todos los sistemas de ventilación deben contar con sistema de humidificación. 
Rev Latin Infect Pediatr 2020; 33 (s1): s52-s69

Cualquier paciente con COVID-19 debe ser manejado en una habitación con presión negativa; ${ }^{29}$ en el caso de no contar con ella, se debe utilizar una habitación con tasa de ventilación mínima de $150 \mathrm{~L} / \mathrm{s}$, la cual se logra con al menos una ventana abierta y una puerta cerrada.

Medidas simples como colocar una mascarilla quirúrgica al paciente por encima de la cánula nasal podrían ayudar a mitigar el esparcimiento del patógeno. ${ }^{16}$ El buen ajuste de la interfaz garantiza un bajo riesgo de transmisión aérea, debido a que no crea una dispersión generalizada del aire exhalado (Figura 7).

\section{MANEJO DEL CHOQUE SÉPTICO EN PACIENTES CON COVID-19}

Podemos reconocer cuando un adolescente tiene incapacidad de mantener TAM $>65 \mathrm{mmHg}$ y lactato $>2 \mathrm{mmol} / \mathrm{L}$ en ausencia de hipovolemia (no es indispensable conocer el lactato, pues se puede basar en la TAM y los signos de hipoperfusión).

El manejo del choque en la primera hora, basándonos en estudios previos, ${ }^{30}$ y las recomendaciones de la OMS ${ }^{1}$ son:
1. Inicio de antimicrobianos.

2. Fluidos en bolos.

3. Vasopresores para la hipotensión persistente.

Para rehidratar, en el caso de adolescentes, se puede aplicar $30 \mathrm{~mL} / \mathrm{kg}$ de un cristaloide (250-1,000 $\mathrm{mL}$ ); en los niños, se les debe administrar $20 \mathrm{~mL} /$ $\mathrm{kg}$ IV en infusión rápida y hasta $40-60 \mathrm{~mL} / \mathrm{kg}$ en la primera hora como límite. No deben administrarse líquidos hipotónicos, ni almidones o gelatinas para rehidratación.

La rehidratación puede dar lugar a una sobrecarga que empeore la insuficiencia respiratoria, por lo que debe ser minuciosa; ésta se puede monitorizar con índices dinámicos de respuesta al aumento de volumen, ${ }^{31}$ tales como mediciones secuenciales del volumen sistólico, variaciones de la presión sistólica y la tensión diferencial, el diámetro de la $\mathrm{VCl}$ y el volumen sistólico como respuesta a los cambios en la presión intratorácica durante la ventilación mecánica. Si el paciente no responde a líquidos y tiene signos de sobrecarga (como ingurgitación yugular, estertores crepitantes, edema pulmonar o hepatomegalia), se deberá reducir o interrumpir su aplicación, principalmente, cuando no se disponga de ventilación mecánica. ${ }^{32}$

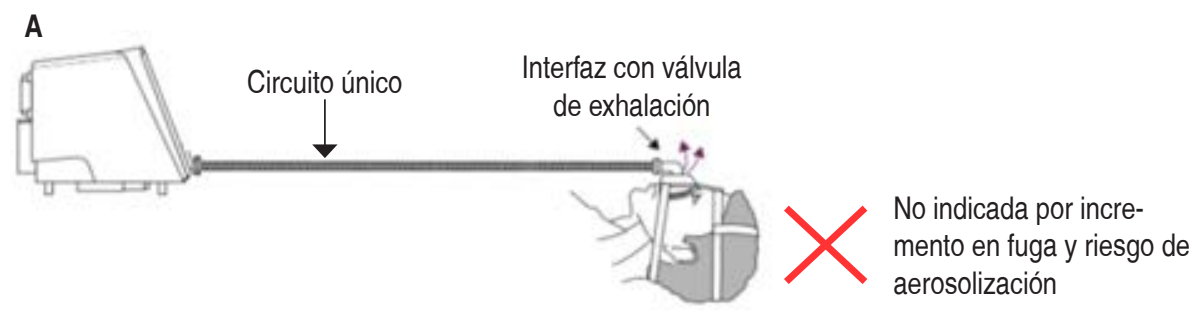

B
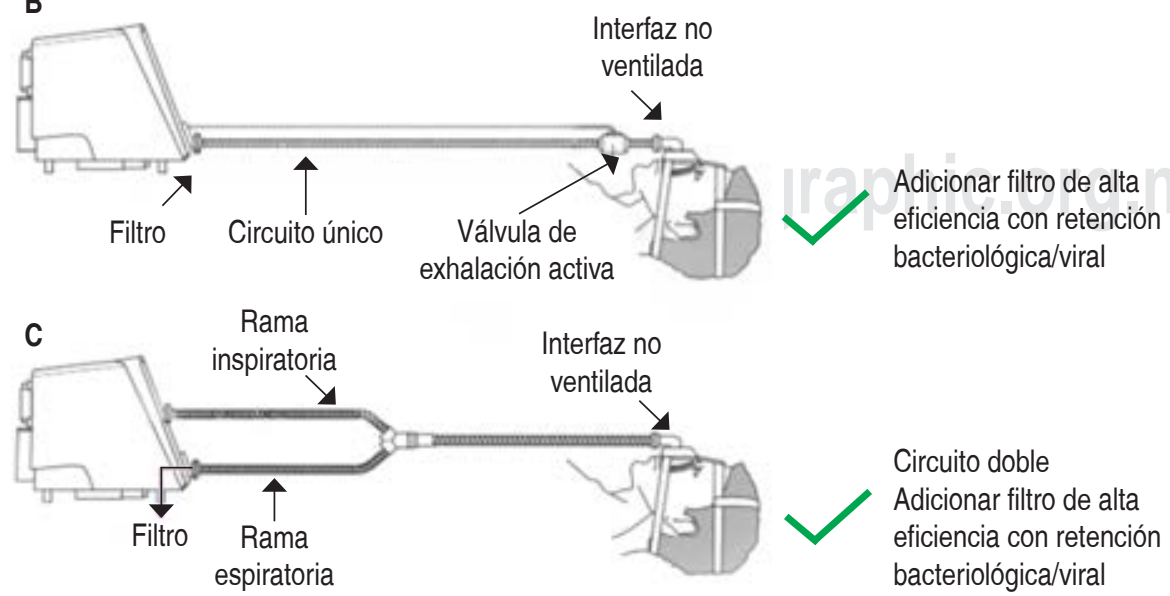

Circuito doble

Adicionar filtro de alta eficiencia con retención bacteriológica/viral
Figura 5:

Tipos de circuitos. Tomado y adaptado de: Simonds AK. ${ }^{28}$ 

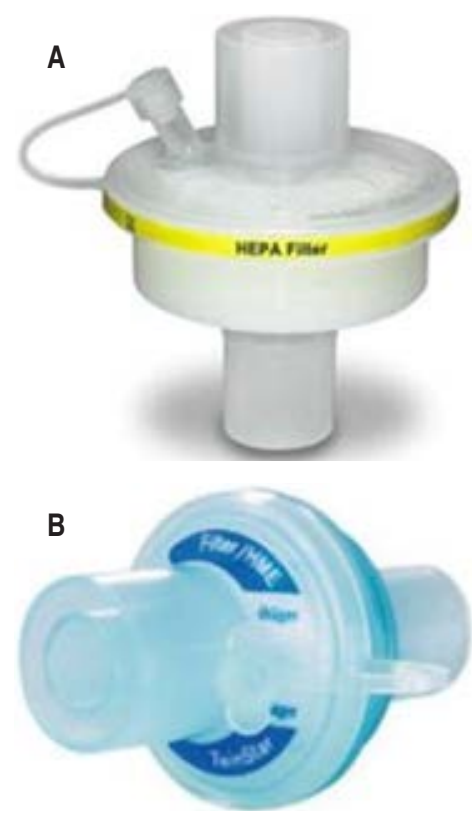

Figura 6:

A) Filtro mecánico HEPA (High Efficiency Particulate Air) con retención bacteriológica/ viral. B) Filtro pediátrico electrostático con retención bacteriológica/ viral.

Los objetivos son:

- $\mathrm{TAM}>65 \mathrm{mmHg}$ en adolescentes o ajustada para la edad.

- Diuresis $>0.5 \mathrm{~mL} / \mathrm{kg} / \mathrm{h}$ en adolescentes y $1 \mathrm{~mL} /$ $\mathrm{kg} / \mathrm{h}$ en niños.

- Reducción de las áreas marmóreas de la piel y mejoría en el llenado capilar y del nivel de consciencia y lactatemia.

En comparación con los cristaloides, los almidones se asocian con un mayor riesgo de muerte y de lesiones renales agudas. Los efectos de las gelatinas son menos claros y son más caros que los cristaloides; además las soluciones hipotónicas reducen el volumen intravascular con menor eficacia que las soluciones isotónicas.

Debemos administrar vasopresores si el choque persiste durante o después de la rehidratación.

Si no se dispone de catéter venoso central, los vasopresores pueden administrarse vía intravenosa periférica en una vena de gran calibre bajo vigilancia estrecha, lo que permitirá detectar signos de extravasación y necrosis tisular local. Si se extravasa, debe suspenderse. También, los vasopresores se pueden administrar vía intraósea. ${ }^{1}$ Si persiste y hay datos de hipoperfusión tisular o insuficiencia cardiaca, a pesar de haber alcanzado la TAM deseada con aporte de líquidos y vaso- presores, debe ser considerado si se requiere un inotrópico, por ejemplo, dobutamina.

La norepinefrina se considera el tratamiento de primera línea en adultos y se le puede añadir epinefrina o vasopresina. Debido al riesgo de taquiarritmia, el uso de dopamina debe considerarse sólo en pacientes con riesgo bajo. En los niños con choque frío (el más común), la epinefrina se considera el tratamiento de primera línea, mientras que la norepinefrina se utiliza en pacientes con choque caliente (menos común).

En la Tabla 4 se mencionan las principales estrategias para prevenir complicaciones de los pacientes que se encuentran en terapia intensiva pediátrica. ${ }^{1,31}$

\section{RECOMENDACIONES PARA REDUCIR EL RIESGO DE INFECCIÓN EN EL PERSONAL DE SALUD}

La tasa de infección en el personal de salud es alta, puesto que nos encontramos en contacto directo con los pacientes y llevamos a cabo procedimientos que, potencialmente, generan aerosoles, tales como la intubación endotraqueal, la ventilación manual, la ventilación con presión positiva, el uso de PAF, la broncoscopia, la aspiración de secreciones y además el transporte o movilización de los pacientes. ${ }^{33}$ Por estas razones, es importante tener en cuenta las recomendaciones que traten de reducir ese riesgo latente; éstas son las recomendaciones de la Sociedad Torácica de China ${ }^{12}$ que fueron enriquecidas por nosotros.

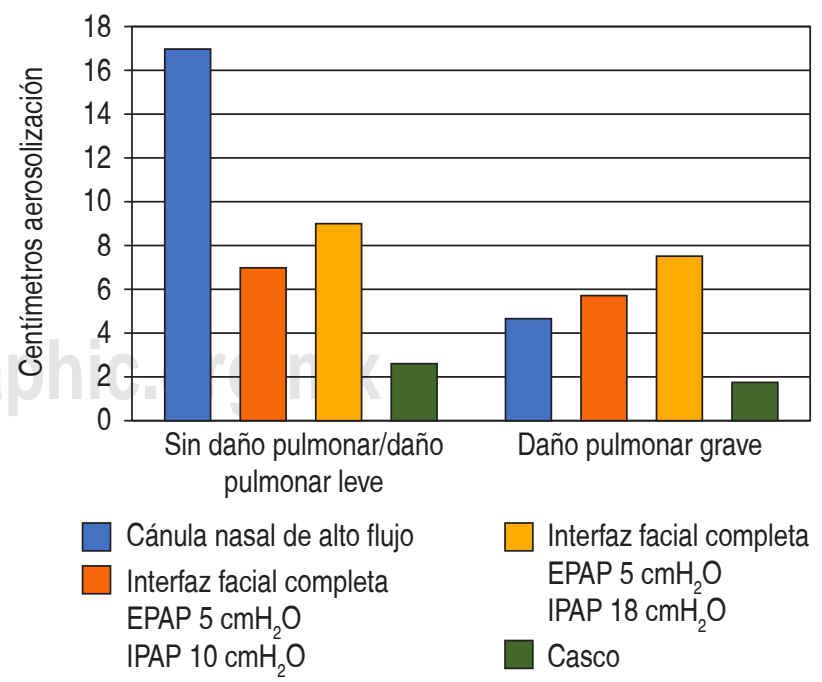

Figura 7: Gráfico comparativo de aerosolización entre diferentes modalidades de soporte ventilatorio., ${ }^{3,17}$ 
Rev Latin Infect Pediatr 2020; 33 (s1): s52-s69

Tabla 4: Estrategias para prevenir complicaciones de los pacientes en Terapia Intensiva Pediátrica.

Para reducir los días de VM

Para reducir la NACS tromboembolismo

Para reducir la incidencia de infecciones asociadas a catéter

Para reducir las úlceras por presión

Para reducir la aparición de úlceras por estrés o sangrado gastrointestinal
Minimizar la sedación continua o intermitente, o interrumpa la sedación continua en cuanto sea posible

Procure intubar al paciente oral y no nasal en adolescentes y adultos

Ponga a la paciente con una elevación de la cabecera de 30-45 grados

Use circuitos de aspiración cerrados. Drene el condensado de las tabuladoras

Use un circuito de ventilador nuevo para cada paciente, cambiarlos si están dañados

Cambie el humidificador cuando funcione mal, si está sucio o cada 5-7 días

Use profilaxis con heparinas de bajo peso molecular o heparina 5,000 U SC c/12 h en adolescentes y adultos sin contraindicaciones. Para aquellos con contraindicaciones, use profilaxis mecánica (dispositivos de compresión neumática intermitente)

Checar el uso adecuado de las líneas, que se inserten de forma estéril y retirarlo lo antes posible.

Cambie al paciente de posición cada $2 \mathrm{~h}$

Administre nutrición enteral tempranamente (en las primeras 24-48 h de admisión)

IBP a los pacientes con riesgo de sangrado:

- Ventilación mecánica por más de 48 h

- Coagulopatía

- Terapia de reemplazo renal

- Enfermedad hepática

- Múltiples comorbilidades

- Falla orgánica múltiple

Para reducir la debilidad muscular Movilizar activamente al paciente en cuanto el curso de la enfermedad y su seguridad lo permita

Las precauciones estándar deben realizarse de manera rutinaria con el recambio de aire en la Unidad de Cuidados Intensivos, 12 veces por hora; hay que considerar que lo ideal es que se cuenten con habitaciones con presión negativa. En cuanto al aislamiento, se deberá ubicar a un paciente por habitación y, en caso de no contar con esta medida, separar a un paciente de otro al menos un metro. No es recomendable ubicar pacientes con VNI y VI en la misma área. ${ }^{12}$

El uso de filtros es muy importante como medida de seguridad; éstos deberán colocarse entre la interfaz del paciente o el tubo endotraqueal y el dispositivo que se esté utilizando, por ejemplo, hay que colocar el filtro viral entre la bolsa autoinflable y la mascarilla, y los filtros en la rama exhalatoria e inhalatoria del ventilador mecánico, también durante el transporte o movilización del paciente. El filtro ideal para colocar en el ventilador es uno que cuente con intercambiador de calor y que tenga alta eficiencia contra virus y bacterias. ${ }^{12}$

El circuito de aspiración debe ser cerrado y se puede utilizar durante siete días; no es necesario cambiarlo. Igualmente, el circuito del ventilador debe permanecer cerrado y se debe evitar las desconexiones, a causa el alto riesgo de contagio. ${ }^{12}$

Se debe evitar la transferencia de pacientes, ya que se producen aerosoles; en caso de ser inevitable, se debe planificar la ruta y avisar al personal que recibirá al paciente. Todos los equipos de diagnóstico deben estar asignados al área específica de cuidados intensivos. $^{34}$

Algunos pacientes en terapia intensiva necesitarán fisioterapia pulmonar, pero se deberán analizar sus riesgos y beneficios. Si es necesaria, debemos colocar una mascarilla quirúrgica al paciente y una sonda de aspiración en la boca para reducir el riesgo de aerosolización. ${ }^{12}$

El uso de cajas de acrílico o aerosol box es una herramienta que intenta reducir el riesgo de exposición a los aerosoles, sin embargo, no tienen evidencia de que reduzcan el riesgo, ya que limitan el campo de actuación y restringen la instrumentación de la vía aérea. Pueden tener cierta utilidad en escenarios donde el riesgo de complicaciones sea mínimo, lo cual es impredecible. De igual manera ocurre con el uso de bolsas de plástico, pues no se conoce ninguna evidencia y, al contrario, al retirarlas generan gran cantidad de aerosoles y un alto riesgo de contagio, por lo cual no las recomendamos. ${ }^{35}$ 


\section{Reanimación cardiopulmonar pediátrica}

Si bien, históricamente, la atención inmediata a través de la reanimación cardiopulmonar ha sido la piedra angular para el éxito de pacientes en estado crítico, ${ }^{36}$ las condiciones actuales proponen un reto para la atención de este tipo de pacientes. ${ }^{37,38}$ En los pacientes pediátricos, la mortalidad reportada ha sido mínima, ${ }^{39-41}$ y las medidas implementadas de distanciamiento físico temprano (cierre de guarderías y escuelas) ha disminuido el contagio entre esta población. Sin embargo, tal como se ha reportado, actualmente en México ${ }^{42}$ y en otros países, ${ }^{43}$ se espera una creciente demanda de servicios de salud en pacientes con enfermedades crónico-degenerativas que acuden por un problema respiratorio, ${ }^{44}$ quienes podrían ameritar cuidados críticos de reanimación cardiopulmonar, lo cual nos obliga a actualizar las directrices del algoritmo de atención.

La decisión de tomar acciones para contrarrestar un paro cardiorrespiratorio dentro del contexto de la enfermedad por SARS-CoV-2 ha suscitado polémi$\mathrm{ca}$, pues, por una parte, debido al escaso éxito de algunas series de casos, se vislumbra un panorama oscuro y de mal pronóstico; ${ }^{45}$ por otro lado, hay consideraciones éticas y en cuanto a la protección del personal de salud ${ }^{46,47}$ por los EGA a tomar en cuenta. ${ }^{36,46}$ La Figura 8 muestra en pacientes pediátricos con COVID-19 las posibles asociaciones con un paro cardiorrespiratorio.
El fundamento de la reanimación cardiopulmonar en el paciente pediátrico es revertir la hipoxia..$^{36,47-49}$ Si bien antes el concepto de realizar todos los esfuerzos necesarios para contrarrestarla no parecía hacer más daño, ahora el hecho de que se ha demostrado que tiene pocos beneficios para el paciente y es potencialmente dañino para el personal de salud, ${ }^{46}$ pone sobre la balanza las intervenciones tempranas sin el EPP mínimo indispensable.

Las diferentes guías internacionales ${ }^{36,48,49}$ llegan a un consenso sobre la relevancia que tiene el uso del EPP para realizar las acciones de reanimación cardiopulmonar. Estas guías mencionan que se deben llevar estrategias para disminuir la exposición a eventos generadores de aerosoles (aerosolización), la necesidad de hacer más eficiente la protección del personal de salud cuando se necesite realizar estos procedimientos, ${ }^{36}$ el uso de dispositivos para mejorar la visualización de la vía aérea al momento de la intubación endotraqueal (videolaringoscopio), la aplicación de filtros de alta eficiencia para reducir aerosoles con partículas virales contaminantes, etcétera.

La adecuación de esfuerzos terapéuticos y la decisión de no llevar a cabo la reanimación cardiopulmonar también es un punto importante, ya sea debido al pronóstico por la propia enfermedad, ${ }^{45,47,50}$ o ya sea por la decisión de familiares y el personal médico. ${ }^{48,49}$ La American Heart Association (AHA) y las asociaciones colaboradoras en las guías

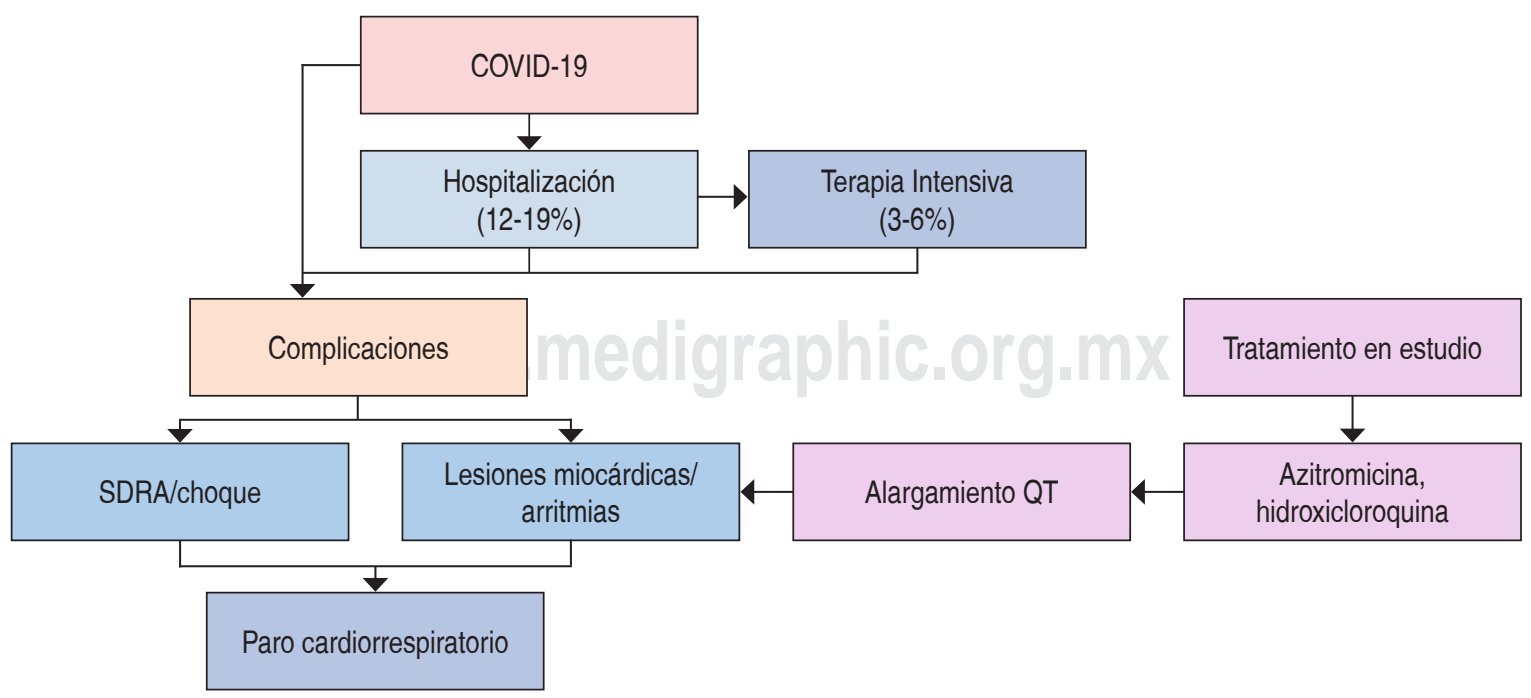

Figura 8: Panorama de la enfermedad y reanimación cardiopulmonar. Adaptado de: Edelson DP et al. ${ }^{36}$ 


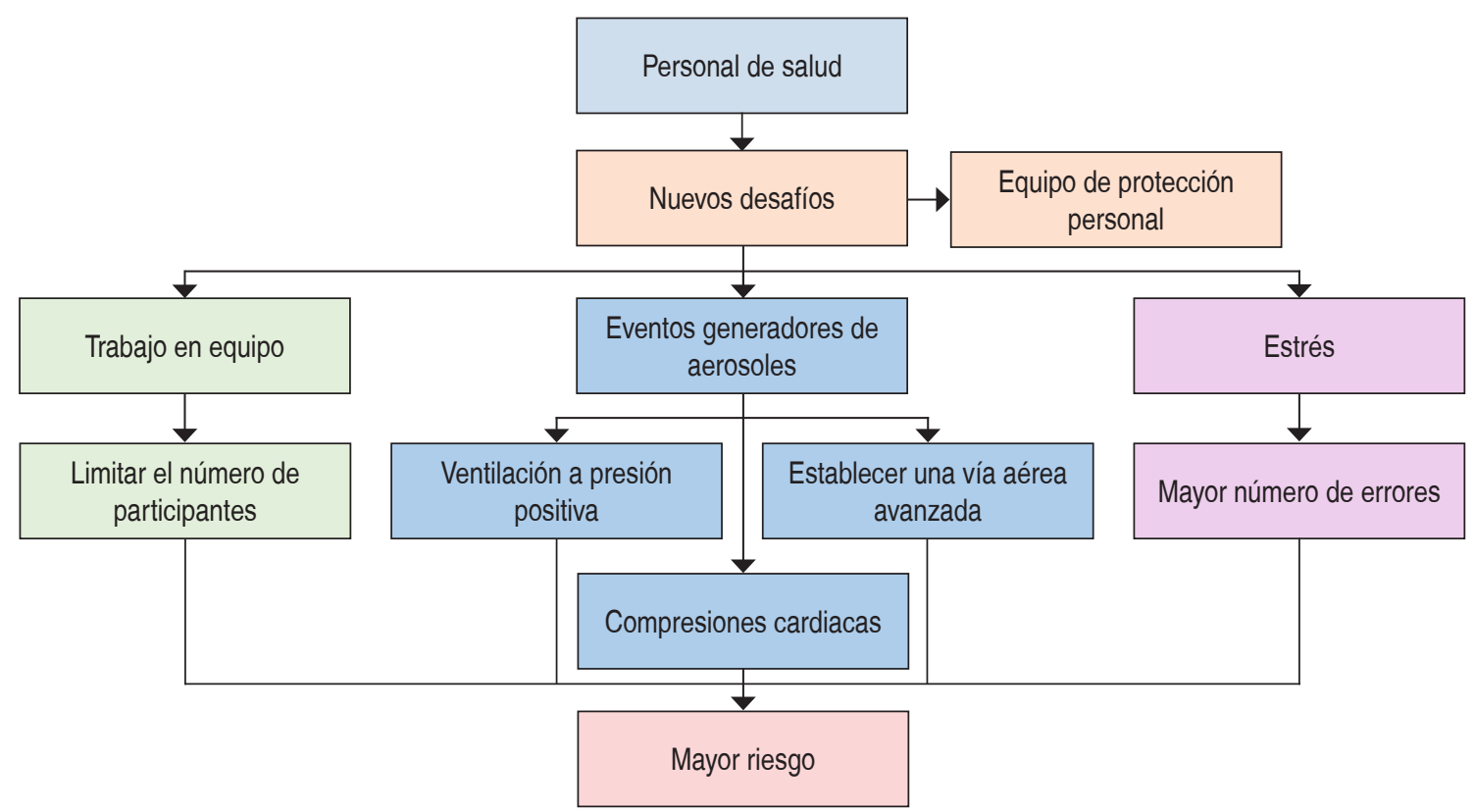

Figura 9: Riesgos para el personal de salud, en la reanimación cardiopulmonar. Adaptado de: Edelson DP et al..$^{36}$

reconocidas no mencionan un punto específico en su algoritmo, ${ }^{36}$ más bien lo refieren como una interrogante a considerar.

Al personal de atención prehospitalaria se les recomienda la capacitación ${ }^{48}$ para el uso y retiro del EPP y la comunicación efectiva con el personal hospitalario para notificar casos sospechosos o confirmados de COVID19. ${ }^{36,48,49}$ Asimismo, al personal se le recomienda, luego del entrenamiento en soporte vital básico, colocar un campo quirúrgico en la región orofacial para evitar EGA, antes de iniciar compresiones cardiacas. ${ }^{36,48,49}$ La AHA recomienda además que, en determinados casos, la aplicación de respiraciones boca a boca o de rescate podrían ser de utilidad en pacientes pediátricos, los cuales son más susceptibles a presentar hipoxia. ${ }^{48}$ En caso de que el reanimador sea un familiar que ya ha estado expuesto a aerosoles propios del paciente o que se tiene sospecha o diagnóstico confirmado de enfermedad por SARS-CoV-2, realizar esta maniobra no aumentaría su riesgo sustancialmente. ${ }^{36,49,51} \mathrm{La}$ Figura 9 nos muestra los riesgos del personal de salud al respecto.

Dependiendo de las series de casos, hasta 19\% de los pacientes con COVID-19 requeriría hospitalización, ${ }^{36}$ e inclusive $6 \%$ necesitará de cuidados intensivos. En el ámbito hospitalario, se hacen las siguientes recomendaciones, las cuales se resumen en la Figura 10:36,37,39
- Monitorización permanente para los pacientes en estado crítico, ya que serán los que más probabilidades tienen de caer en un paro cardiorrespiratorio. ${ }^{36,37}$

- Movilización del paciente a un espacio físico (cuarto) con presión negativa; ${ }^{36}$ en ese espacio donde permanecerá, es necesario mantener la puerta cerrada.

- Ajustar parámetros ventilatorios para coordinarse con la reanimación cardiopulmonar. ${ }^{36}$ Esto incluye lo siguiente:

- Cambiar la modalidad de ventilador para permitir una ventilación asincrónica con las compresiones.

- Incrementar la $\mathrm{FiO}_{2}$ a 100\%.

- Ajustar el modo ventilatorio por presión y limitar la necesaria para generar una elevación adecuada del tórax $(6 \mathrm{~mL} / \mathrm{kg}$ de peso ideal, o 4-6 mL/kg en neonatos).

- Apagar el sensor de disparo para evitar la activación de disparos por parte del ventilador con cada compresión.

- Ajustar la frecuencia respiratoria a 10 rpm en adultos y a $30 \mathrm{rpm}$ en neonatos.

- Ajustar la PEEP para evitar barotrauma y adecuar el retorno venoso.

- Ajustar alarmas.

- Realizar las medidas necesarias en cualquier momento que sea oportuno. De esta manera, se asegurará la adecuada colocación del tubo endotraqueal. 
Así, hasta no determinar una forma más eficiente de tratar a los pacientes en estos momentos críticos, como son el inicio de la vida o la posibilidad del final de la misma, se deben seguir las recomendaciones actuales para salvaguardar su bienestar; además, hay que recordar que jamás se debe descuidar la seguridad de quien brinda la atención en salud, pues el personal que se expone pone en riesgo a su equipo de trabajo y a quienes atiende, en el contexto de enfermedades contagiosas, en este caso, la causada por SARS-CoV-2.

\section{Broncoscopia y traqueostomía}

La broncoscopia y la traqueostomía son herramientas que tienen indicaciones precisas, las cuales deben ser reestructuradas, debido a la pandemia por COVID-19. Presentamos los principales lineamientos a seguir para realizar ambas prácticas, basándonos en la revisión de la literatura y modificaciones en nuestro entorno.

El personal está en contacto cercano con el paciente durante la broncoscopia, y esto puede generar aerosoles por los pacientes al toser o respirar de manera forzada, por lo que se considera que existe mayor riesgo de infección. Por ello, se deben conocer las medidas de seguridad y precaución contra contagios ${ }^{33}$ teniendo en cuenta estrategias que pueden ayudar al personal a protegerse, siendo la principal el uso de Equipo de Protección Personal (EPP) completo antes de realizar el procedimiento: gorro, gafas protectoras cerradas, pijama de tela (encima de ésta debe tener pijama desechable), bata desechable impermeable, cubrebocas N95, cubrebotas o cubrezapatos y guantes estériles (uno o doble par). Nosotros sugerimos que, previo a abandonar el

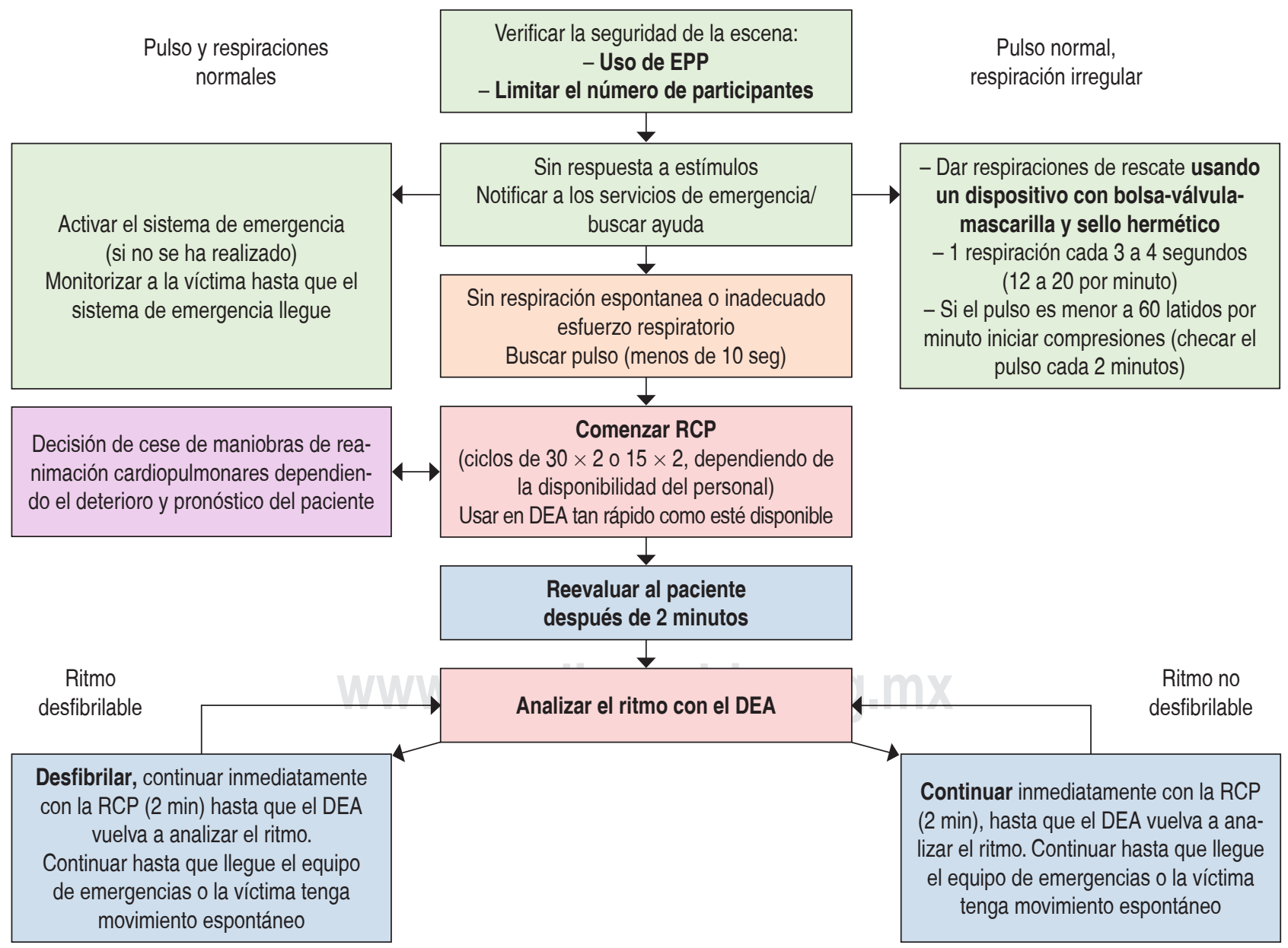

Figura 10: Resumen de las modificaciones de las principales guías de reanimación cardiopulmonar pediátrica básica. 11,13,14 
Rev Latin Infect Pediatr 2020; 33 (s1): s52-s69

instituto, se realice un aseo corporal total con agua y jabón, y posteriormente cambiarse de ropa. Otras medidas recomendadas incluyen hacer un buen sello a la mascarilla facial durante la preoxigenación con ambas manos, mantener al paciente en un adecuado plano anestésico, disminuir el tiempo de ventilación y evitar la presión excesiva.

En pacientes adultos, las guías sugieren el acceso transnasal, ya que tiene menor riesgo de aerosolización..$^{52,53}$ En el paciente pediátrico, debe evaluarse si la mejor alternativa es la intubación orotraqueal del paciente con una cánula con globo insuflado con manómetro y sin fugas, o la colocación de mascarilla laríngea de un tamaño adecuado con una fijación óptima para evitar desplazamientos. ${ }^{4,33}$

La American Association for Bronchology and Interventional Pulmonology (AABIP),${ }^{54}$ en sus recomendaciones de 2020, menciona las indicaciones diagnósticas para realizar una broncoscopia. A continuación, las mencionamos y agregamos otras terapéuticas de nuestro entorno:

- En pacientes con ventilación mecánica invasiva con pruebas de vías respiratorias superiores o lavado traqueal no concluyente para confirmar el diagnóstico de COVID-19, principalmente después de dos pruebas de hisopado nasofaríngeo negativo o un lavado traqueal negativo, ya que es mayor la sensibilidad de RT-PCR para SARS-CoV-2/COVID-19 en LBA (93\%) en comparación con el aspirado bronquial o esputo $(72 \%)$ e, incluso, el hisopado naso y orofaríngeo $(63 \%) .{ }^{55}$

- En pacientes con ventilación mecánica invasiva y con sospecha de un diagnóstico diferencial que afecte el manejo clínico.

- Urgencias: hemoptisis masiva, obstrucción endobronquial significativa y estenosis grave benigna o maligna.

- Cuando hay sospecha de obstrucción de la vía aérea con urgencia relativa o no urgente: estenosis moderada de vía aérea, masa pulmonar y linfadenopatía mediastinal o hiliar.

- Para el apoyo en la intubación de pacientes con vía aérea difícil.

- En pacientes con atelectasias persistentes que ocasionen dificultad a la ventilación.

- En pacientes con alteraciones radiológicas no explicadas por la infección por COVID-19 que requieran descartar alteraciones de la vía aérea.
Las contraindicaciones son relativas e inherentes a la realización de la broncoscopia; ésta, por cualquier motivo electivo, dentro de lo posible debe posponerse hasta la remisión completa de la infección. ${ }^{54}$

No está indicada la realización de broncoscopias repetidas o seriadas a los pacientes.

\section{Dentro de las recomendaciones generales se encuentran:}

- El procedimiento se debe realizar preferentemente en la sala de aislamiento del paciente, terapia intensiva o sala de broncoscopia con presión negativa (cuando esté disponible). En caso contrario, se debe garantizar una adecuada ventilación. ${ }^{52,54}$

- Se debe reducir al mínimo la cantidad de personal médico y enfermería durante el procedimiento.

- Dentro de lo posible, deberán utilizarse broncoscopios desechables.

- Habrá que considerar dentro del protocolo de desinfección de la sala el uso de luz ultravioleta durante 30 minutos entre un paciente y otro. ${ }^{52}$

- Se debe usar un termómetro portátil; en caso de presentar fiebre, se suspenderá el procedimiento.

- Se debe insertar un filtro viral entre la máscara facial y el dispositivo de ventilación, además se puede colocar una sonda de succión constante en la boca.

- Se debe minimizar la extracción repetida del broncoscopio de la vía aérea y, en caso de ser necesario, suspender la ventilación transitoria en el momento de la extracción o reinserción.

- En caso de contar con broncoscopios reutilizables, una vez terminado el procedimiento, se recomienda utilizar reprocesadores cerrados automáticos, los cuales después del proceso de limpieza y desinfección de alto nivel, irrigan alcohol a $75 \%$ a través del canal de trabajo. Además, puede humedecerse un paño con alcohol a $75 \%$ y dar un aseo final al exterior, según las recomendaciones de opiniones de expertos en el reprocesamiento de endoscopios y broncoscopios a nivel mundial. ${ }^{56}$ De no ser posible, realice una limpieza y desinfección de alto nivel de acuerdo con los procedimientos convencionales, haciendo pasar al final alcohol a $75 \%$ con un paño a través del canal de trabajo y en el exterior, tal como ya se ha comentado. Luego de este procedimiento, deje secar. 


\section{Realización de la traqueostomía}

Cuando se considera que se realizará una traqueostomía por COVID-19, debemos tener en cuenta las consideraciones que ha continuación se señalan. Dichas aportaciones están basadas en la ENTUK, ${ }^{57}$ las guías de otorrinolaringología publicadas por médicos de Singapur ${ }^{58}$ y la Sociedad Española de Otorrinolaringología y Cirugía de Cabeza y Cuello, 59 las cuales son discutidas y enriquecidas constantemente:

- Para realizar una traqueostomía, al igual que una broncoscopia, se debe tener presente al mínimo personal necesario, usar EPP, ${ }^{58-60}$ realizarla en salas con presión negativa, utilizar material desechable y, posteriormente, limpiar profundamente la sala con luz UV por 30 minutos.

- Todo paciente debe tener una prueba de detección de COVID-19 antes de realizarse el procedimiento. ${ }^{57}$

- Evaluar la indicación de la traqueostomía:

a) En caso de ser una obstrucción de la vía aérea reversible, considere si se puede realizar una intubación rutinaria y, si es el caso, seguir los algoritmos de vía aérea difícil.

b) En caso de ser una urgencia por obstrucción de la vía aérea irreversible, tome las precauciones necesarias y realice el procedimiento:

- Debe usarse traqueotomías no fenestradas y con globo, ${ }^{58}$ además tenga presente las consideraciones necesarias en niños, ya que las cánulas neonatales no cuentan con globo y es más probable que tengan fugas.

- Coloque un humidificador pasivo con filtro viral y trate de desconectarlo lo menos posible. De ser necesario, hágalo distalmente.

- Se sugiere valorar con anestesiología, si es posible, la relajación del paciente para evitar que tosa, así como para reducir el uso de succión durante el procedimiento. De ser necesario, utilice un circuito cerrado con filtro para partículas virales. ${ }^{58,59,61}$

Cuando el procedimiento es electivo, lo mejor es considerarlo que se realice hasta las 2 o 3 semanas de intubación, sobre todo cuando el paciente ya se encuentra estable y tenga una prueba negativa para COVID-19. 57,58

Existe controversia entre si son de elección las traqueostomías percutáneas ${ }^{59}$ o quirúrgicas, ${ }^{60,62}$ pero se considera que las quirúrgicas suelen ser más rápidas y las percutáneas tienen mayor manipulación, además de que requieren desconexión y reconexión del circuito. ${ }^{58}$

Dentro de los cuidados de traqueostomía, se sugiere evitar cambiar el tubo hasta que COVID-19 haya pasado, ${ }^{57}$ mantener el globo siempre inflado y verificar que no haya fugas.

En conclusión, tanto la broncoscopia como la traqueostomía son procedimientos necesarios, cuyo uso debe ser evaluado de forma adecuada durante la pandemia, de modo que sea un procedimiento eficaz para el paciente y seguro para el personal.

\section{REFERENCIAS}

1. Organización Mundial de la Salud (OMS). Manejo clínico de la infección respiratoria aguda grave presuntamente causada por el nuevo coronavirus (2019-nCoV) Orientaciones provisionales [Internet]. Versión del 18 de junio de 2020 (orientaciones provisionales). Disponible en: https://apps.who.int/iris/bitstream/handle/10665/330938/ WHO-nCoV-Clinical-2020.3-spa.pdf

2. Centro de Coordinación de Alertas y Emergencias Sanitarias. Dirección General de Salud Pública, Calidad e Innovación. Manejo pediátrico en atención primaria de COVID-19 [Internet]; 2020. Disponible en: https:// www.mscbs.gob.es/profesionales/saludPublica/ccayes/ alertasActual/nCov-China/documentos/Manejo_pediatria_ ap.pdf

3. World Health Organization. Oxygen therapy for children: a manual for health workers [Internet]. WHO Library Cataloguing-in-Publication Data; 2016, pp. 1-57. Available from: https://apps.who.int/iris/bitstream/ handle/10665/204584/9789241549554_eng.pdf;jsessionid= 3771BCCE16FF08061123B70DF03F9F4F? sequence $=1$

4. Detsky ME, Jivraj N, Adhikari NK, Friedrich JO, Pinto R, Simel DL et al. Will this patient be difficult to intubate? the rational clinical examination systematic review. JAMA. 2019; 321 (5): 493-503.

5. Rimensberger PC, Cheifetz IM, Jouvet P, Thomas NJ, Willson DF, Erickson $S$ et al. Ventilatory support in children with pediatric acute respiratory distress syndrome: proceedings from the pediatric acute lung injury consensus conference. Pediatr Crit Care Med. 2015; 16 (5): S51-S60.

6. Moss M, Huang DT, Brower RG, Ferguson ND, Ginde AA, Gong MN et al. Early neuromuscular blockade in the acute respiratory distress syndrome. N Engl J Med. 2019; 380 (21): 1997-2008

7. NIH NHBI ARDS Clinical Network Mechanical Ventilation Protocol. ARDS Net - table [Internet] Trial; 2000, pp. 6-7. Available from: http://www.ardsnet.org/files/ventilator protocol_2008-07.pdf

8. Combes A, Hajage D, Capellier G, Demoule A, Lavoué S, Guervilly $C$ et al. Extracorporeal membrane oxygenation for severe acute respiratory distress syndrome. N Engl J Med. 2018; 378 (21): 1965-1975.

9. Fan E, Del Sorbo L, Goligher EC, Hodgson CL, Munshi L, Walkey AJ et al. An official American Thoracic Society/ European Society of intensive care medicine/society of critical care medicine clinical practice guideline: Mechanical 
Rev Latin Infect Pediatr 2020; 33 (s1): s52-s69

ventilation in adult patients with acute respiratory distress syndrome. Am J Respir Crit Care Med. 2017; 195 (9): 12531263.

10. Dwyer J. What doctors on the front lines wish they'd known a month ago. New York Times [Internet]. New York Times. 2020. Available from: https://www.nytimes.com/2020/04/14/ nyregion/new-york-coronavirus.html

11. Arabi YM, Mandourah Y, Al-Hameed F, Sindi AA, Almekhlafi GA, Hussein MA et al. Corticosteroid therapy for critically ill patients with middle east respiratory syndrome. Am J Respir Crit Care Med. 2018; 197 (6): 757-767.

12. Respiratory Care Committee of Chinese Thoracic Society. Expert consensus on preventing nosocomial transmission during respiratory care for critically ill patients infected by 2019 novel coronavirus pneumonia. Zhonghua Jie He He Hu Xi Za Zhi. 2020; 43 (4): 288-296. Available from: http:// rs.yiigle.com/yufabiao/1182334.htm

13. Comisión de Ingeniería Médica y Sanitaria del Colegio y la Asociación de Ingenieros Industriales de Madrid. Protocolo de ventilación múltiple con un solo ventilador para situaciones de pandemia/catástrofe sanitaria [Internet]; 2020, pp. 1-8. Disponible en: https://portal.coiim.es/uploads/ files/1272103d8ad60aaa44d221909c1f60f64a9ac636.pdf

14. Assessment CE. Single ventilator use to support multiple patients single ventilator use to support multiple patients [Internet]. Elsevier; 2020. Available from: https://www. elsevier.com/_data/assets/pdf_file/0009/1000314/COVIDECRI_HTA_Single-Ventilator-Use-Multiple-Patients.pdf

15. World Health Organization (WHO). Clinical management of severe acute respiratory infection when COVID-19 is suspected (v1.2); 2020, p. 1-21. Available from: https://www. who.int/publications-detail/clinical-management-of-severeacute-respiratory-infection-when-novel-coronavirus-(ncov)infection-is-suspected

16. Whittle JS, Pavlov I, Sacchetti AD, Atwood C, Rosenberg MS. Respiratory support for adult patients with COVID-19. J Am Coll Emerg Physicians Open. 2020: 10.1002/ emp2.12071. Available from: https://onlinelibrary.wiley.com/ doi/pdf/10.1002/emp2.12071

17. Martínez Carrasco C. Ventilación no invasiva en pediatría. Rev Patol Respir. 2014; 17 (Suppl 1): 65-66.

18. Torres CP, Bustos FD. Ventilación no invasiva en insuficiencia respiratoria aguda pediátrica: rol del terapeuta ventilatorio. Neumol Pediatr [Internet]. 2017; 12 (4): 151160. Disponible en: https://www.neumologia-pediatrica. cl/wp-content/uploads/2017/10/151-160_ventilacion-noinvasiva.pdf

19. Brochard L. Mechanical ventilation: invasive versus noninvasive. Eur Respir J Suppl. 2003; 47: 31s-37s.

20. Lyons $C$, Callaghan $M$. The use of high-flow nasal oxygen in COVID-19. Anaesthesia [Internet]. 2020; 75 (7): 843847. Available from: https://onlinelibrary.wiley.com/doi/ $\mathrm{pdf} / 10.1111 / \mathrm{anae} .15073$

21. Muñoz-Bonet J. Predictive factors for the outcome of noninvasive ventilation in pediatric acute respiratory failure. Pediatr Crit Care Med. 2010; 11: 675-680.

22. Pilar Orive FJ, López Fernández YM. Oxigenoterapia de alto flujo. An Pediatr Contin [Internet]. 2014; 12 (1): 25-29. Disponible en: https://continuum.aeped.es/files/articulos/ OAF.APC.pdf

23. Esquinas A. Guía esencial de metodología en ventilación mecánica no invasiva en pediatría. 2a. ed. Madrid: Panamericana; 2018, p. 823.
24. WeVent. Respiratory management protocol of patients with SARS-COV-2 (COVID-19) [Internet]. Vol. 2. Available from: https://www.formacionsanitaria.eu/documentos/ Recomendations_WeVent.pdf

25. Rabec C, Rodenstein D, Leger P, Rouault S, Perrin C, GonzalezBermejo J. Ventilator modes and settings during non-invasive ventilation: effects on respiratory events and implications for their identification. Thorax. 2011; 66 (2): 170-178.

26. Jouvet $P$, Thomas NJ, Willson DF, Erickson $S$, Khemani $R$, Smith $L$ et al. Pediatric acute respiratory distress syndrome: consensus recommendations from the pediatric acute lung injury consensus conference. Pediatr Crit Care Med. 2015; $16(5)$ : 428-439.

27. Cohen M. Recomendaciones para el manejo de la insuficiencia respiratoria aguda hipoxémica por COVID-19 [Internet]. 2020. Disponible en: https://alatorax.org/ es/videos/w/recomendaciones-para-el-manejo-de-lainsuficiencia-respiratoria-aguda-hipoxemica-por-covid-19

28. Simonds AK. Handbook noninvasive ventilation. Sheffield, UK: European Respiratory Society; 2015.

29. Rochwerg B, Brochard L, Elliott MW, Hess D, Hill NS, Nava $S$ et al. Official ERS/ATS clinical practice guidelines: noninvasive ventilation for acute respiratory failure. Eur Respir J. 2017; 50 (2): 1602426.

30. Davis AL, Carcillo JA, Aneja RK, Deymann AJ, Lin JC Nguyen TC et al. American College of Critical Care Medicine clinical practice parameters for hemodynamic support of pediatric and neonatal septic shock. Crit Care Med. 2017; 45 (6): 1061-1093.

31. Rhodes A, Evans LE, Alhazzani W, Levy MM, Antonelli $M$, Ferrer $R$ et al. Surviving sepsis campaign: international guidelines for management of sepsis and septic shock: 2016. Intensive Care Med. 2017; 43 (3): 304-377.

32. Schultz MJ, Dunser MW, Dondorp AM, Adhikari NKJ, lyer S, Kwizera A et al. Current challenges in the management of sepsis in ICUs in resource-poor settings and suggestions for the future. Intensive Care Med. 2017; 43 (5): 612-624.

33. Brewster DJ, Chrimes N, Do TB, Fraser K, Groombridge CJ, Higgs A et al. Consensus statement: safe airway society principles of airway management and tracheal intubation specific to the COVID-19 adult patient group. Med J Aust. 2020; 212 (10): 472-481.

34. World Health Organization (WHO). Global infection prevention and control network. Infection prevention and control during health care when COVID-19 is suspected [Internet]. 2020. Available from: https://apps.who.int/iris/bitstream/ handle/10665/112656/9789241507134_eng.pdf;jsessionid=F9 DD8829ECA57EFB5F88EC959B36217F?sequence $=1$

35. Critico P, Lesso AV, Antonio J, Lares C, León OD. Bioseguridad y manejo de la vía aérea en el paciente crítico. Sociedad Científica Internacional EMIVA [Internet]. 2020. Disponible en: https://www.academia.edu/42561243/Bioseguridad_y Manejo_de_la_Via_Aerea_del_Paciente_Critico_COVID-19

36. Edelson DP, Sasson C, Chan PS, Atkins DL, Aziz $\mathrm{K}$, Becker LB et al. Interim guidance for basic and advanced life support in adults, children, and neonates with suspected or confirmed COVID-19: From the emergency cardiovascular care committee and get with the guidelines-resuscitation adult and pediatric task forces of the American Heart Association. Circulation [Internet]. 2020; 141 (25): e933-e943. Available from: https://www.ahajournals.org/doi/epub/10.1161/ CIRCULATIONAHA.120.047463 
37. Jordan RE, Adab P, Cheng KK. Covid-19: risk factors for severe disease and death. BMJ [Internet]. 2020; 368: m1198. Available from: https://www.bmj.com/content/ bmj/368/bmj.m1198.full.pdf

38. Ruan S. Likelihood of survival of coronavirus disease 2019. Lancet Infect Dis [Internet]. 2020; 20 (6): 630-631. Available from: https://www.thelancet.com/pdfs/journals/laninf/ PIIS1473-3099(20)30257-7.pdf

39. CDC COVID-19 Response Team. Coronavirus disease 2019 in children: United States, February 12-April 2, 2020. MMWR [Internet]. 2020; 69 (14): 422-426. Available from: https://www.cdc.gov/mmwr/volumes/69/wr/pdfs/ mm6914e4-H.pdf

40. Ludvigsson JF. Systematic review of COVID-19 in children shows milder cases and a better prognosis than adults. Acta Paediatr [Internet]. 2020; 109: 1088-1095. Available from: https://onlinelibrary.wiley.com/doi/pdf/10.1111/apa.15270

41. Qiu H, Wu J, Hong L, Luo Y, Song Q, Chen D. Clinical and epidemiological features of 36 children with coronavirus disease 2019 (COVID-19) in Zhejiang, China: an observational cohort study. Lancet Infect Dis. 2020: S14733099(20)30397-2.

42. Gobierno de México. Comunicado Técnico Diario. Información internacional y nacional sobre nuevo coronavirus con corte a 18 de abril de 2020 [Internet]. Disponible en: https://coronavirus.gob.mx/2020/04/18/ conferencia-18-de-abril/

43. Dong $Y$, Mo X, Hu Y, Qi X, Jiang F, Jiang $Z$ et al. Epidemiological Characteristics of 2143 Pediatric Patients With 2019 Coronavirus Disease in China. Pediatrics [Internet]. 2020; e20200702. Available from: https://pediatrics.aappublications.org/content/pediatrics/ early/2020/03/16/peds.2020-0702.full.pdf

44. Dayal D. We urgently need guidelines for managing COVID-19 in children with comorbidities. Acta Paediatr [Internet]. 2020; 109 (7): 1497-1498. Available from: https:// onlinelibrary.wiley.com/doi/epdf/10.1111/apa.15304

45. Shao F, Xu S, Ma X, Xu Z, Lyu J, Ng M et al. In-hospital cardiac arrest outcomes among patients with COVID-19 pneumonia in Wuhan, China. Resuscitation [Internet]. 2020; 151: 18-23. Available from: https://reader.elsevier.com/ reader/sd/pii/S0300957220301428?token=C06E89BF4A43 6D4E5E03D684E0A21366454E99D985EC4223ED38A9C5 5EC1D2436616D9C34F7253A79992E80DDDD8BAA2

46. Fritz Z, Perkins GD. Cardiopulmonary resuscitation after hospital admission with covid-19. BMJ [Internet]. 2020; 369: m1387. Available from: https://www.bmj.com/content/ bmj/369/bmj.m1387.full.pdf

47. Mahase E, Kmietowicz Z. Covid-19: doctors are told not to perform CPR on patients in cardiac arrest. BMJ [Internet]. 2020; 1282: m1282. Available from: https://www.bmj.com/ content/bmj/368/bmj.m1282.full.pdf

48. Resuscitation Council (UK). Resuscitation Council UK Statements on COVID-19 (Coronavirus), CPR and Resuscitation [Internet]. Resuscitation Council (UK); 2020. Available from: https://www.resus.org.uk/sites/default/ files/2020-06/Resuscitation Council UK Statement on COVID-19 in relation to CPR and resuscitation in first aid and community settings 13052020 .pdf

49. New Zealand Resuscitation Council. COVID-19 Modifications to essential life support [Internet]. New Zealand Resuscitation Council. 2020. Available from: https:// www.nzrc.org.nz/covid-19/\#update-march-24
50. Yang Y, Peng F, Wang R, Yange M, Guan K, Jiang T et al The deadly coronaviruses: The 2003 SARS pandemic and the 2020 novel coronavirus epidemic in China. J Autoimmun [Internet]. 2020; 109: 102434. Available from: eader.elsevier. $\mathrm{com} / \mathrm{reader} / \mathrm{sd} / \mathrm{pii} / \mathrm{S} 0896841120300470$ ?token $=735 \mathrm{~B} 919 \mathrm{C} 8$ 9A22A3CC2AE2E6EBA1C0C26031534F38E2B89FD993DB CDC4D6CE97260918DA55339BD5491BDAC5A56FD839D

51. Organización Mundial de la Salud. Atención en el domicilio a pacientes presuntamente infectados por el nuevo coronavirus (COVID-19) que presentan síntomas leves, y gestión de sus contactos [Internet]. 2020. Disponible en: https://apps.who.int/iris/bitstream/ handle/10665/331397/WHO-nCov-IPC-HomeCare-2020.2spa.pdf?sequence $=1$ \&isAllowed $=y$

52. Group of Interventional Respiratory Medicine, Chinese Thoracic Society. Expert consensus for bronchoscopy during the epidemic of 2019 Novel Coronavirus infection (Trial version). Zhonghua Jie He He Hu Xi Za Zhi [Internet] 2020; 43: E006. Available from: http://www.scopus.com/ inward/record.url?eid=2-s2.0-84865607390\&partnerID=tZO tx3y1\%0Ahttp://books.google.com/books?hl=en\&amp;Ir=\&a $\mathrm{mp} ; \mathrm{id}=2 \mathrm{LIMMD} 9 F V X k C \& a m p ; o i=f n d \& a m p ; p g=P R 5 \& a m p ; d$ $q=$ Principles+of+Digital+Image+Processing+fundamental+t echniques\&amp;ots=HjrHeuS

53. Cai SJ, Wu LL, Chen DF, Li YX, Liu YJ, Fan YQ et al. Analysis of bronchoscope-guided tracheal intubation in 12 cases with coronavirus disease 2019 under the personal protective equipment with positive pressure protective hood. Zhonghua Jie He He Hu Xi Za Zhi [Internet]. 2020; 43 (4): 332-334. Available from: http://www.ncbi.nlm.nih.gov/ pubmed/32133829

54. Wahidi MM, Lamb C, Murgu S, Musani A, Shojaee S, Sachdeva A et al. American Association for Bronchology and Interventional Pulmonology (AABIP) statement on the use of bronchoscopy and respiratory specimen collection in patients with suspected or confirmed COVID-19 infection. J Bronchology Interv Pulmonol. 2020; 27 (4): e52-e54.

55. Saavedra-Trujillo $\mathrm{CH}$. Consenso colombiano de atención, diagnóstico y manejo de infección por SARS-COV-2/ COVID-19 en establecimientos de atención de la salud. Recomendaciones basadas e el consenso de expertos e informadas en la evidencia. Asociación Colombiana de Infectología. Infectio [Internet]. 2020; 24 (3): 1-153. Disponible en: https://www.revistainfectio.org/index.php/ infectio/article/view/851/946

56. Olympus. Reprocesamiento de equipos endoscópicos. Disponible en: https://www.olympus.es/medical/es/ Productos-y-soluciones/Soluciones-médicas/Higiene-yreprocesado/

57. ENTUK. Tracheostomy guidance during the COVID [Internet]. Tracheostomy guidance during the COVID-19 Pendemic. Available from: https://www.entuk.org/ tracheostomy-guidance-during-covid-19-pandemic

58. Tay JK, Khoo ML, Loh WS. Surgical considerations for tracheostomy during the COVID-19 pandemic: lessons learned from the severe acute respiratory syndrome outbreak. JAMA Otolaryngol Head Neck Surg [Internet]. 2020; 146 (6): 517-518. Available from: https://jamanetwork. com/journals/jamaotolaryngology/fullarticle/2764033

59. Díaz de Cerio-Canduela P, Ferrandis-Perepérez E, Parente-Arias P, López-Álvarez F, Sistiaga-Suarez JA. Recomendaciones de la Sociedad Española de Otorrinolaringología y Cirugía de Cabeza y Cuello 
Rev Latin Infect Pediatr 2020; 33 (s1): s52-s69

para la realización de traqueotomías en relación a pacientes infectados por coronavirus COVID-19. Acta Otorrinolaringol Esp [Internet]. 2020; 71 (4): 253-255. Disponible en: https://reader.elsevier.com/reader/sd/pii/ S000165192030042X?token=D9DE7247910D616479065 999203CEB1C14F6855C405DF53C775C3DCF98959667 01CA7A190F3C1F75F603DC1753D93232

60. Chee VW, Khoo ML, Lee SF, Lai YC, Chin NM. Infection control measures for operative procedures in severe acute respiratory syndrome-related patients. Anesthesiology. 2004; 100 (6): 1394-1398.
61. Kwan A, Fok WG, Law KI, Lam SH. Tracheostomy in a patient with severe acute respiratory syndrome. $\mathrm{Br} \mathrm{J}$ Anaesth. 2004; 92 (2): 280-282.

62. Tien HC, Chughtai T, Jogeklar A, Cooper AB, Brenneman $F$. Elective and emergency surgery in patients with severe acute respiratory syndrome (SARS). Can J Surg. 2005; 48 (1): $71-74$

Correspondencia:

Dra. Rosangela Del Razo Rodríguez

E-mail: rosangelarr@yahoo.com 